\title{
Crisaborole and Apremilast: PDE4 Inhibitors with Similar Mechanism of Action, Different Indications for Management of Inflammatory Skin Conditions
}

\author{
Jan M. Kitzen 1,2, Joseph V. Pergolizzi Jr.,3,4, Robert Taylor Jr. ${ }^{3}$, Robert B. Raffa ${ }^{4,5,6}$ \\ ${ }^{1}$ Kitzen Pharmaceutical Consulting, Collegeville, PA, USA \\ ${ }^{2}$ Temple University School of Medicine, Philadelphia, PA, USA \\ ${ }^{3}$ NEMA Research, Inc., Naples, FL, USA \\ ${ }^{4}$ Neumentum, Inc., Palo Alto, CA, USA \\ ${ }^{5}$ University of Arizona College of Pharmacy, Tucson, AZ, USA \\ ${ }^{6}$ Temple University School of Pharmacy, Philadelphia, PA, USA \\ Email: rraffa@temple.edu
}

How to cite this paper: Kitzen, J.M., Pergolizzi Jr., J.V., Taylor Jr., R. and Raffa, R.B. (2018) Crisaborole and Apremilast: PDE4 Inhibitors with Similar Mechanism of Action, Different Indications for Management of Inflammatory Skin Conditions. Pharmacology \& Pharmacy, 9, 357-381. https://doi.org/10.4236/pp.2018.99028

Received: July 27, 2018

Accepted: September 7, 2018

Published: September 10, 2018

Copyright (c) 2018 by authors and Scientific Research Publishing Inc. This work is licensed under the Creative Commons Attribution International License (CC BY 4.0).

http://creativecommons.org/licenses/by/4.0/

\begin{abstract}
Two selective phosphodiesterase-4 (PDE4) inhibitors-viz., crisaborole (Eucrisa $^{\circledR}$, Pfizer) and apremilast (Otezla ${ }^{\circledR}$, Celgene)-have recently received approval by the United States Food and Drug Administration for the treatment of related but different dermatologic skin conditions (viz., atopic dermatitis and plaque psoriasis, respectively). The purpose of this review is to summarize the underlying biochemistry and pathophysiology associated with these dermatologic conditions, review the chemistry, pharmacology and safety of each of these products, and present preclinical and clinical evidence that may help explain why these two PDE4 inhibitors offer new treatment options for these skin conditions.
\end{abstract}

\section{Keywords}

Crisaborole, Apremilast, Phosphodiesterase, PDE4, Inflammation, Cytokines, Interleukins, cAMP

\section{Introduction}

There are numerous treatment options available for the management of the inflammatory skin conditions atopic dermatitis (AD), psoriasis and psoriatic arthritis. Topical corticosteroids, disease modifying antirheumatic drugs (DMARDs 
such as methotrexate, leflunomide and others), topical calcineurin inhibitors and skin moisturizing agents have been the mainstay of therapy for several of these inflammatory skin conditions, however these also present some safety concerns. More recently new types of biological agents have become widely available for treating these conditions and considerably expanded the options for treatment. There are now several new monoclonal antibodies available that have been designed to target specific pro-inflammatory molecules in the interleukin family of cytokines involved in the pathology of inflammatory skin conditions such as ustekinumab $\left(\right.$ Stelara $\left.^{\circledR}\right)$ and secukinumab $\left(\right.$ Cosentyx $\left.{ }^{\circledR}\right)$, among many others. There are several disadvantages associated with biological therapies since they must be administered either subcutaneously or intravenously, making it somewhat difficult for the patient. In addition, several of these biologicals, which are immunosuppressant agents, have important safety concerns such as increased risk of opportunistic infections, and the need for ongoing laboratory monitoring. Significant costs are also associated with these types of products [1] and must be factored in as part of the decision in selecting therapy. Another relatively new approach to the management of these conditions has been through the targeted inhibition of phosphodiesterase 4, causing increases in intracellular cyclic AMP (cAMP) which leads to multiple favorable therapeutic effects including a decrease in the production of several of the pro-inflammatory mediators. Crisaborole (Eucrisa ${ }^{\circledR}$, Pfizer) and apremilast (Otezla ${ }^{\circledR}$, Celgene) are both selective inhibitors of the isozyme phosphodiesterase-4 (PDE4). Yet crisaborole is available as a topical ointment (2\%) and is indicated for the treatment of atopic dermatitis [2], whereas apremilast is available as oral tablets $(10,20$ and $30 \mathrm{mg})$ and is indicated for the treatment of plaque psoriasis and for psoriatic arthritis [3]. This review is not intended to serve as a comprehensive comparison of all of the pharmacological therapies for treating the various skin conditions and is meant to describe the pharmacological activity and safety of these two PDE4 inhibitors and examine their differences and potential role in the management of these inflammatory skin conditions.

\section{Overview of Phosphodiesterases}

Shortly after the landmark discovery of cyclic adenosine monophosphate (cAMP) by Rall and Sutherland 60 years ago [4], it was found that enzymes rapidly hydrolyze cAMP to adenosine monophosphate (AMP), thus making it difficult to measure low concentrations of cAMP in tissues. The enzyme that was found to be mainly responsible for the rapid hydrolysis of the cyclic ribonucleotide was shown to be a phosphodiesterase (PDE) [5]. The investigators then discovered that various nonspecific inhibitors of the PDE enzymes, such as theophylline, and other xanthine derivatives, improved the ability to measure minute quantities of cAMP with greater accuracy, since the inhibitors prevented its rapid destruction. These early investigations were the first to show that cAMP was an intracellular mediator or second messenger for specific hormones and neurotransmitters in various tissues, and that PDE was an important cellular mechanism for terminating the biological actions of the mediator [6]. 
Over the ensuing decades, thousands of studies have been devoted to furthering an understanding of the physiology and biochemistry of cAMP and how it is regulated. Over the years many isoforms (isozymes) of PDE have been identified, substrate specificity is more thoroughly understood, detailed structural analyses have been performed, and specific genetic loci for various isoforms have been well characterized [7].

The cyclic nucleotide phosphodiesterases are now known to be a superfamily of over 100 isoenzymes comprised of 11 different families of phosphohydrolases derived from 21 genes [7]. PDEs are capable of selectively hydrolyzing two important nucleotide substrates: cAMP and cyclic guanosine monophosphate (cGMP). The various isoforms of the PDE enzymes differ in their relative selectivity for cAMP and cGMP as shown in Table 1 . The molecular site of this hydrolysis is the 3' phosphoester bond of either of these nucleotides as shown in Figure 1. cGMP is also a second messenger within cells, and in general, increases

Table 1. Selected phosphodiesterase isoforms and their relative substrate specificity and tissue distribution [7] [8].

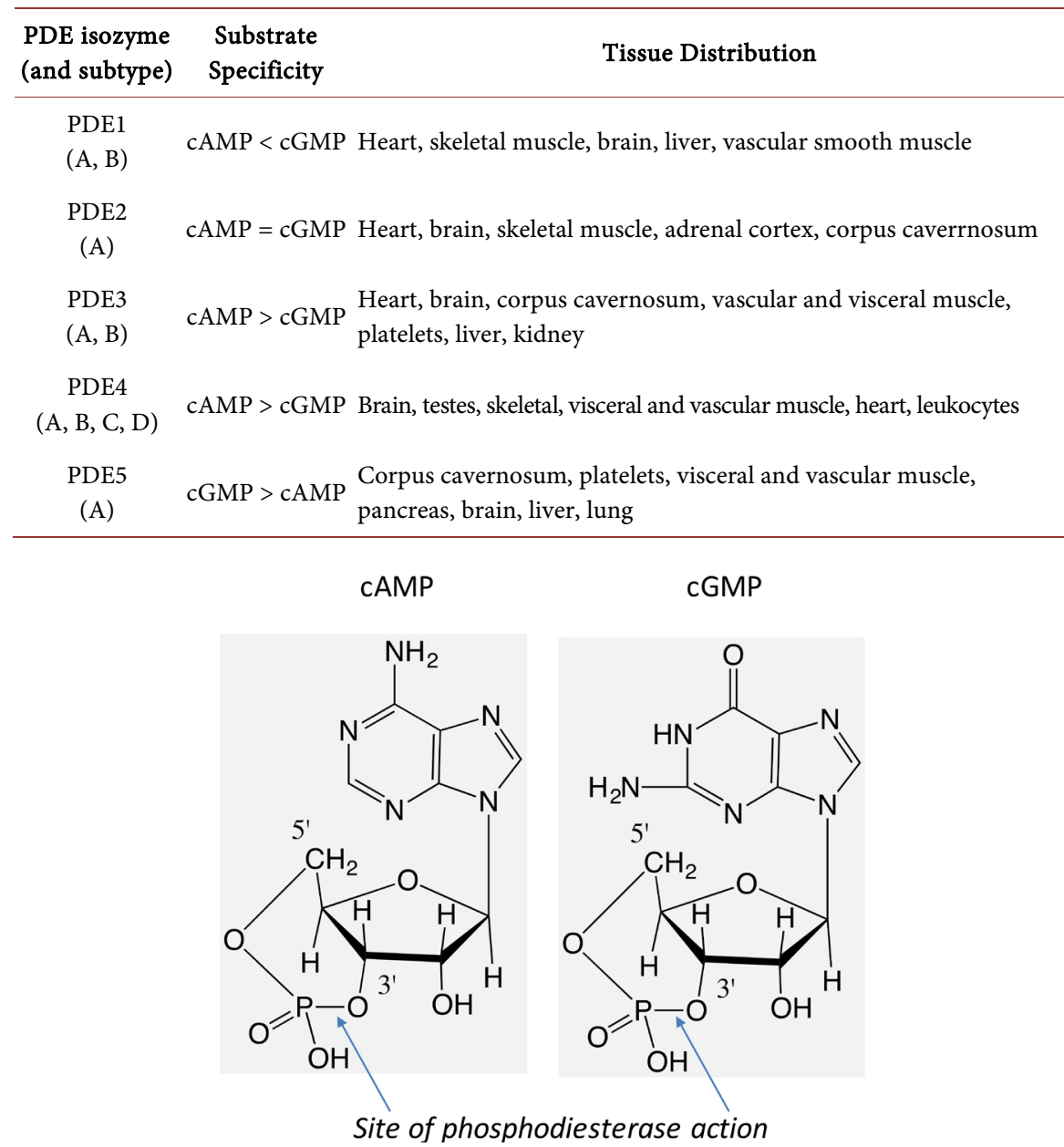

Figure 1. Chemical structures of cAMP and cGMP showing the 3 ' site of bond cleavage by phosphodiesterases producing inactive ribonucleotides + phosphate. The various isoforms of PDE have different affinities for the two substrates. 
in cGMP cause opposite effects from those that are caused by increases in cAMP. The 5'AMP- and 5'GMP-hydrolyzed nucleotides (+phosphate) subsequently become inactive in signal transduction pathways, effectively terminating their biological activity.

\section{Nomenclature}

The current nomenclature associated with PDE enzymes has evolved into a complex system primarily related to the genetics of their regulation based on their genetic loci and allele type. Historically, the PDE enzymes were typically classified on the basis of known regulatory functions and were commonly referred to using a Roman Numeral system based upon substrate specificity, modes of regulation and their elution orders from DEAE cellulose column chromatography [7] [9]. This system is no longer used and a system of including species, gene family (Arabic numerals), allele type and gene variant is in use today. A simpler version of the current nomenclature utilizes the Human Genome Nomenclature consisting of only the family type and optionally includes the gene variant subtype. This simpler version will be used in this review. As an example, the PDE type four inhibitors will be referred to simply as "PDE4" except when biochemical assays of subtype specificity such as "PDE4B" are cited for clarification purposes. The biological activity and tissue distribution for a portion of the 11 families of the various PDE isoenzymes are summarized in Table 1.

Also shown in Table 1, it is the relatively wide range of tissue distribution for five of the $11 \mathrm{PDE}$ isoenzymes, suggesting that even "selective" isoenzyme-specific inhibitors exert inhibition in several "off-target" tissues in addition to the "target" of therapeutic interest, possibly resulting in adverse events. Of the 11 gene families that code for various isoenzymes, this review focuses on the PDE4 subtype since that is the target for the two drugs discussed.

\section{The PDE4 Isoenzyme Family}

The PDE4 family is comprised of four genes (A through D) that can generate more than 20 gene products by means of alternate start sites and alternative splicing [7]. All four of the genetic subtypes are selective for cAMP with low $K_{\mathrm{m}}$ values $\left(K_{\mathrm{m}}\right.$ value refers to the dissociation constant of the enzyme substrate complex). Low $K_{\mathrm{m}}$ values indicate strong, high affinity binding of substrate to the active site of the enzyme) ranging from 1 to $10 \mu \mathrm{M}$ [7]. Molecular structures of PDEs have a conserved carboxy-terminal catalytic region, while the $N$-terminal regions differ among families, subfamilies and specific isoforms [10]. It is through the $N$-terminal regions that specific subcellular locations are possible and each of the four PDE4 subtypes has a unique $N$-terminal targeting domain. The catalytic domain of PDE4 has been extensively studied and x-ray crystal structures reveal details of the active site that enabled the design of family-specific inhibitors [10] [11].

As shown in Table 1, PDE4 enzymes are distributed throughout many tissues 
including the brain, the pulmonary vasculature, leukocytes, and smooth (e.g., vascular) and skeletal muscles, among others. Fischmeister et al. [12] have shown that in the cardiovascular system, PDE4 isoenzymes are compartmentalized in such a manner that inhibition leads to very limited effects on cardiovascular parameters such as resting blood pressure, cardiac rate, or myocardial contractility. The major role of cAMP in the cardiovascular system involves its activation during $\beta$-adrenergic receptor stimulation, which leads to large increases in intracellular levels of cAMP [10] [13]. One of the important adverse events associated with PDE4 inhibitors is emesis, thought to be due to inhibition of PDE4 in the brain [7]. For example, adverse events associated with orally administered apremilast include diarrhea, nausea and vomiting (see below) [3].

\section{Intracellular Functions of cAMP}

cAMP is an intracellular second messenger, and mediates the actions in numerous downstream pathways in various cell types. cAMP is formed when an extracellular first messenger such as a hormone (e.g. estrogen, ACTH), chemokine, lipid mediator (e.g. $\mathrm{PGE}_{2}$ ), neurotransmitter (e.g. dopamine), or drug interact or bind to specific cell surface receptors linked to a seven transmembrane-spanning $G$ protein coupled receptor (GPCR) that ultimately stimulates the enzyme adenylyl cyclase [14] (AC, also sometimes referred to as adenylate cyclase) [15]. Activation of adenylyl cyclase catalyzes the formation of cAMP from adenosine triphosphate (ATP). AC isoforms are primarily membrane bound, although at least one soluble form is known [15]. Following the formation of cAMP, the most prominent next effect is the activation of cAMP dependent protein kinase A (PKA). PKA then initiates successive signaling cascade reactions through the phosphorylation of specific amino acid residues on various target proteins. These are too numerous to discuss further in this short review, therefore only those pathways relevant to inflammation associated with psoriasis or atopic dermatitis and how PDE inhibition affects these are considered here.

cAMP, its effector proteins and downstream targets can lead to a variety of effects depending on cell type and signaling context. In the types of inflammatory skin disorders considered here, cAMP is known to have important roles in various types of skin cells including melanocytes, keratinocytes and fibroblasts [16]. cAMP formation can be stimulated by corticotropin releasing hormone (CRH) which then modulates immune functions through changes in expression of cell surface adhesion molecules and cytokine production [17]. Both atopic dermatitis and psoriasis are characterized by defective functions in these skin cell types. In addition, $\mathrm{T}$-cells play a major role in the pathogenesis of these inflammatory skin conditions and cAMP has important regulatory functions on inflammatory pathways in T-cells and other immune cell types [16]. Intracellular levels of cAMP are critical to modulating these inflammatory mediators. For example, in T-cells and other types of immune cells involved in inflammation, increases in intracellular cAMP concentration inhibit the production of pro-inflammatory 
mediators such as tumor necrosis factor-alpha (TNF- $\alpha$ ), interferon beta (IFN- $\beta$ ), interferon- $\gamma$ (IFN- $\gamma$ ), interleukin-12 (IL-12), leukotriene $\mathrm{B}_{4}\left(\mathrm{LTB}_{4}\right)$, and other locally released cytokines and proteins. In addition to suppressing the production of pro-inflammatory mediators, increases in cAMP promote the release of anti-inflammatory mediators such as IL-10, which has powerful inhibitory actions on immune cell activation. T-cells are known to have a role in the pathogenesis of both psoriasis and atopic dermatitis [18] [19] and both IL-17 and IL-23 are effective targets for other drugs used to treat psoriasis [18].

It seems clear that drugs capable of increasing intracellular concentrations of cAMP could lead to favorable therapeutic effects through cAMP-mediated modulation of multiple factors involved in inflammatory skin conditions.

\section{Atopic Dermatitis}

Atopic dermatitis $(\mathrm{AD})$ is a chronic inflammatory skin condition characterized by pruritis, erythema, scaling, lichenification (hardening of the skin) and recurrent eczematous lesions. While a defective epidermal barrier is a common factor in all patients with $\mathrm{AD}$, it can still be a highly variable condition. $\mathrm{AD}$ is associated with elevated levels of immunoglobulin E (IgE) in about $80 \%$ of affected persons [20] and Hanifin and Chan showed over 20 years ago that there were increased intracellular levels of PDE activity in leukocytes obtained from AD patients [21] and Salpietro et al. later showed that plasma levels of cAMP were significantly lower in children with acute AD compared to a healthy control group [22]. A typical dermal lesion appearance is shown in Figure 2. The rashes can occur on any part of the body, yet can vary with age. For example, in infants the rashes are more common on the face, scalp, hands and feet, while in children rashes more commonly present in the bends of the elbows and knees. In adolescents and adults rashes more commonly occur on wrists, ankles and eyelids, in addition to the bends of the elbows and knees [23] [24]. AD is well known to be associated with several other types of allergies including food allergy, bronchial asthma, and allergic rhinitis, commonly referred to as the Atopic March [24] [25].

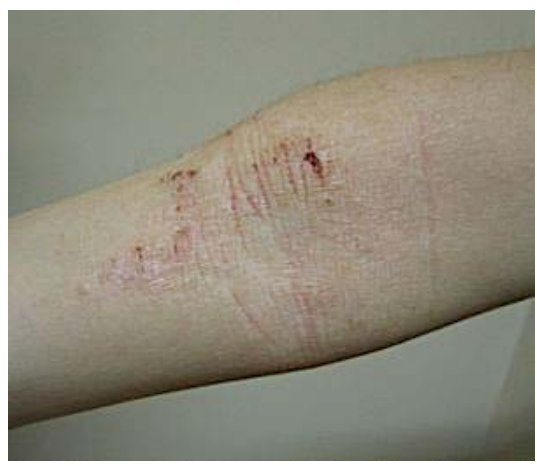

Figure 2. Atopic dermatitis on inner skin of elbow

(https://upload.wikimedia.org/wikipedia/commons/thumb/1/1a/Atopy2010.JPG/300px-A topy2010.JPG). 


\subsection{Diagnosis and Symptoms}

Although several diagnostic guidelines are available, the diagnosis of $\mathrm{AD}$ is primarily based upon guidelines established by the American Academy of Dermatology and is determined by certain essential clinical features as well as specific exclusionary conditions [20]. AD is basically indistinguishable from other causes of dermatitis. Essential features of clinical AD include:

- Pruritis;

- Eczema (acute, subacute and chronic) with age-specific patterns such as facial, neck and extensor involvement in infants and children; current or previous lesions in any age group and sparing of the groin and axillary regions.

A diagnosis of $\mathrm{AD}$ also requires the exclusion of several other dermatologic conditions including, but not limited to scabies, seborrheic dermatitis, psoriasis, contact dermatitis and several other conditions. On occasion, skin biopsies or other tests such as serum IgE, patch and/or genetic testing may be helpful in ruling out other skin conditions.

Patients with $\mathrm{AD}$ have dry, sensitive skin due to changes in the epidermis, which maintains the hydration state of the skin and is an important barrier to the environment by preventing environmental irritants, allergens and microbes from entering the body.

\subsection{Prevalence and Etiology}

$\mathrm{AD}$ is the most common chronic inflammatory skin disease, can affect people from all races and in $95 \%$ of cases it occurs before 5 years of age. The prevalence rate for $\mathrm{AD}$ in the United States is $10 \%-12 \%$ in children and $0.9 \%$ in adults, although 1\% - 3\% may be affected [24] [26]. International prevalence in developed countries ranges from $15 \%-30 \%$ in children and $2 \%-10 \%$ in the adult population. There is a slight female preponderance in children of 1.3:1.

The etiology of $\mathrm{AD}$ is not fully understood. However, evidence suggests that a combination of genetic and environmental factors coupled with skin barrier defects and dysregulation of immune function appear to be involved. Multiple triggers have been identified including diet, allergens, stress, irritants and the most common trigger is colonization of the skin by Staphylococcus aureus [24] [27]. A family history of $\mathrm{AD}$ is common and the strongest known genetic risk factor is a lack of coding for filaggrin, which is a protein produced by differentiating keratinocytes and known to be a key epidermal barrier protein essential for epithelial integrity.

\subsection{Histopathology and Pathophysiology}

$\mathrm{AD}$ is histologically complex and the details of the extensive immunopathology, molecular biology, pathophysiology and genetics associated with this condition are reviewed elsewhere and will be summarized here [19] [25] [28]. Skin barrier defects are the most significant pathologic findings in $\mathrm{AD}$. The barrier function of the skin is primarily located in the outermost layer of the skin, the stratum 
corneum (keratin) layer as shown in Figure 3.

Histologically the lesions associated with $\mathrm{AD}$ reveal epidermal intercellular edema (spongiosis) accompanied with perivascular infiltration by various cell types including macrophages, monocytes, lymphocytes, eosinophils, dendritic cells and other types of immune cells [16]. Plaques are characterized by epidermal hypertrophy, thickening and hyperkeratosis. This complex mixture of immune cell types leads to the release of many types of pro-inflammatory mediators that contribute to the inflammation of the skin. Proteomic profiling and immunohistologic studies in patients with $\mathrm{AD}$ have revealed the presence of subclinical inflammation, a down-regulation of epithelial differentiation with a decrease in skin barrier proteins as a cause of transepidermal loss of water [28]. In addition, abnormalities in the tight junction function located in the epidermal layer may also contribute to the decrease in skin barrier function. These findings emphasize the importance of maintaining skin hydration (emollient therapy) as part of AD therapy management.

\subsection{Treatment of AD}

Since one of the main features of $\mathrm{AD}$ is dry skin due to the disruption in skin barrier function, the mainstay of treatment is to maintain hydration of the skin with emollients combined with topical steroid therapy to suppress cutaneous inflammation. Emollients should be applied several times a day to hydrate the outermost layer of the skin (keratin, Figure 3) and fortify the lipid barrier. Corticosteroids suppress the inflammatory response via multiple mechanisms of action which lead to inhibition of lymphocyte activity in the skin which, in turn, decreases the release of pro-inflammatory cytokines such as TNF- $\alpha$ and

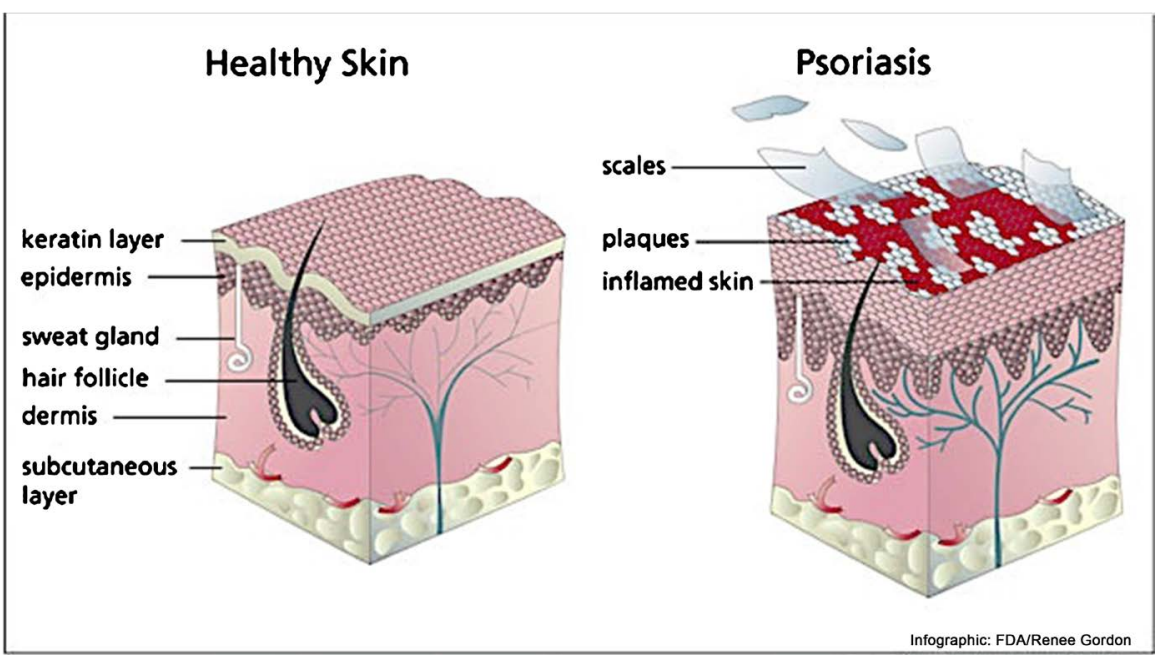

Figure 3. Healthy vs. psoriatic skin features. In psoriasis, an activated immune system triggers the skin to reproduce every 3 - 4 days, building up on the outer layers (epidermis and keratin). The epidermis thickens, blood flow increases and reddens the skin, and silver-gray scales cover it (https://permanent.access.gpo.gov/lps1609/www.fda.gov/fdac/graphics/2004graphics/pso riasisinfog.jpg). 
interleukins. Many corticosteroids are available in a range of anti-inflammatory potencies from low potency hydrocortisone to intermediate potency fluocinolone acetonide to high potency agents such as betamethasone valerate. Potencies are partially affected by the salt form used and the base (cream, ointment, gel) used in formulation. Steroid therapy is associated with many potential adverse events, especially with long-term use ( $>3$ months) and this is a limiting factor governing their usefulness. Common adverse effects associated with topical steroid therapy include thinning of the skin, atrophy, petechiae and worsening of acne [29]. Systemic toxicity is also a risk and may lead to suppression of the hypopituitary adrenal axis possibly resulting in adrenal insufficiency, and osteoporosis in adults. For a more detailed discussion of topical steroids and their safety the reader is referred to Ference \& Last [30].

Other therapeutic treatment options available include the calcineurin inhibitors such as picremolimus (Elidel ${ }^{\circledR}$ ) and tacrolimus (Protopic ${ }^{\circledR}$ ). Calcineurin antagonists are functional immunosuppressants that were originally developed as an alternative to systemic steroid therapy to suppress tissue rejection following transplantation. They inhibit T-cell activation and cytokine release by inhibiting the action of calcineurin in the skin. Meta-analysis studies of controlled clinical trials showed that tacrolimus was similar in efficacy as topical steroids in the management of $\mathrm{AD}$ while picremolimis was less obvious [31].

\section{Role of PDE4 Inhibitor Therapy in the Management of AD and Psoriasis}

The PDE4 isoenzyme is an ideal target for new drugs designed to treat AD and psoriasis for a variety of reasons:

- X-ray crystal structures of the catalytic domain of PDE4 isozymes make the design of small molecule inhibitors feasible [11] [32].

- Experimental and clinical evidence have demonstrated that increases in intracellular levels of cAMP will lead to inhibition of formation of multiple mediators of inflammation in several cell types known to be responsible for these inflammatory skin conditions [33].

- Effective therapy with PDE4 inhibitors may allow patients to decrease the use of topical steroids and calcineurin inhibitors, resulting in a decreased incidence of adverse events.

- Since the effects of increasing intracellular cAMP lead to similar inhibition of release of pro-inflammatory cytokines (TNF- $\alpha$, IL-17, IL-23), therapeutic efficacy can be achieved without the need for adding monoclonal antibody products (i.e. adalimumab (Humira ${ }^{\circledR}$ Abbvie), secukinumab, ustekinumab) that must be injected and are more-costly.

- Since increasing intracellular levels of cAMP exerts a broader range of favorable effects, compared to selective inhibition of interleukins, such as inhibition of histamine release, this strategic approach may be more effective in relieving the itch associated with $\mathrm{AD}$ compared to therapy with more specific molecular targets [33] [34] [35]. 


\section{Plaque Psoriasis}

Psoriasis is a chronic, immune-mediated disorder that mainly manifests as skin lesions, but joints and organs can also be affected [36]. Plaque psoriasis (vulgaris) is the most common manifestation, as shown in Figure 4. Symptoms can range in severity from very mild (a few scattered red, scaly plaques) to involvement of almost the entire surface of the body. One classification scheme, by the National Psoriasis Foundation, classifies the disease according to the surface area affected: $<3 \%$ mild, $3 \%-10 \%$ moderate, and $>10 \%$ severe [37].

The various types of psoriasis are summarized in Table 2. The most common

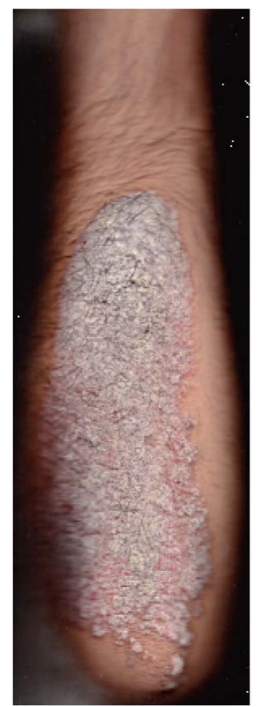

\section{Plaque psoriasis}

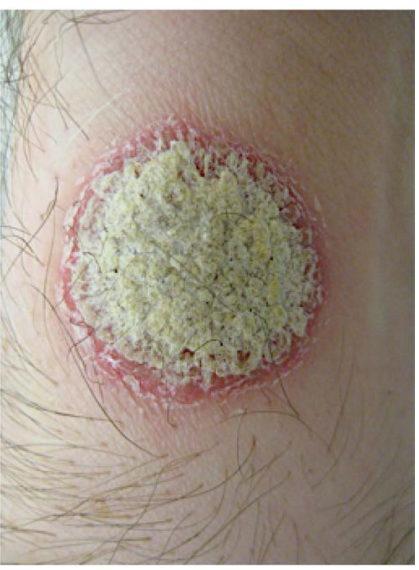

Figure 4. Plaque psoriasis: Note the elevated lesions with easily demarcated boundaries. Plaques can be irregular or oval and the thickened epidermis contains an infiltrate of neutrophils and lymphocytes

(https://commons.wikimedia.org/w/index.php?search=Plaque+psoriasis\&title=Special:Se arch\&go=Go\&searchToken=do5rkpzgb1b63xx9u6rd07kjx).

Table 2. Types of psoriasis.

\begin{tabular}{cl}
\hline Type & \multicolumn{1}{c}{ Description } \\
\hline $\begin{array}{c}\text { Plaque } \\
\text { (Vulgaris) }\end{array}$ & $\begin{array}{l}\text { The most common form; appears as raised red patches covered with silvery white } \\
\text { build-up of dead skin cells, most often on the scalp, knees, elbows and lower back; } \\
\text { often itchy and painful, and can crack and bleed. }\end{array}$ \\
Guttate & $\begin{array}{l}2^{\text {nd }} \text { most common form ( 10\%); appears as small, dot-like lesions; often starts in } \\
\text { childhood or young adulthood, and can be triggered by a strep infection. }\end{array}$ \\
Inverse & $\begin{array}{l}\text { Appears as very red lesions in body folds (e.g., behind the knee, under the arm or } \\
\text { in the groin); may appear smooth and shiny. Many people have another type of } \\
\text { psoriasis elsewhere on the body at the same time. }\end{array}$ \\
& $\begin{array}{l}\text { Characterized by white pustules (blisters of noninfectious pus) surrounded by red } \\
\text { skin; can occur on any part of the body, but most often on the hands or feet. }\end{array}$ \\
& $\begin{array}{l}\text { A particularly severe form that leads to widespread, fiery redness over most of the } \\
\text { body; can cause severe itching and pain, and make the skin shed in sheets. It is rare } \\
\text { (3\% of people who have psoriasis during their life time), and generally appears on } \\
\text { people who have unstable plaque psoriasis, can be life-threatening. }\end{array}$ \\
Erythrodermic
\end{tabular}


types (plaque, guttate, inverse, pustular) are not life-threatening, but negatively affect quality of life. Rarer types (erythrodermic) can be life-threatening. It may progressively worsen with age, or wax and wane in its severity; the degree of severity depends on inheritance and environmental factors.

\subsection{Symptoms}

The most common signs and symptoms of plaque psoriasis are [38]:

- Plaques of red, inflamed skin, often covered with loose, silver-colored scales as depicted in Figure 3. These plaques may be itchy and painful and sometimes crack and bleed. In severe cases, the plaques will grow and merge into one another, covering large areas.

- Disorders of the fingernails and toenails, including discoloration and pitting of the nails. The nails may also begin to crumble or detach from the nail bed.

- Scaly plaques on the scalp.

- Small areas of bleeding where the involved skin is scratched.

Suggestive of the endogenous component of the disease, the dermatologic symptoms can often be bilateral in manifestation. Certain events, such as stress, skin injuries, infections, or reactions to some medicines, can cause flare-ups in symptoms. The reduction in quality of life issues lead to a higher prevalence of psychosocial issues such as anxiety and depression [39].

In addition to the skin symptoms and substantial negative effects on quality of life, psoriasis is associated with comorbidities, particularly psoriatic arthritis (see below) and cardiovascular disease. Comorbid cardiovascular disease (atherosclerosis and vascular inflammation) is the leading cause of death among patients with psoriasis [40]. Patients with severe forms of psoriasis have been reported to have a 7-fold greater risk of myocardial infarction compared to matched controls, although there is some uncertainty if it is this high [41] [42].

\subsection{Prevalence and Etiology}

The worldwide prevalence of all types is estimated to range from $1 \%-8.5 \%$ (equivalent to more than 125 million people) [43]. The prevalence of psoriasis among adults ages 20 years and older in the United States is about 3.2\% (equivalent to about 7 - 7.5 million people) [44]. Among those 20 - 59 years of age, prevalence is highest in Caucasians (3.6\%), followed by African Americans (1.9\%), and Hispanics (1.6\%) [44]. Although the symptoms can manifest at any age, onset of the typical case occurs during two age ranges: 18 - 39 years of age and 50 69 years of age [43]. It appears to affect males and females about equally.

There is a rather strong genetic component to psoriasis, as revealed in epidemiologic studies of twins [45] [46]. Identical (monozygotic) twins were found to have a 2- to 4-fold higher concordance than fraternal (dizygotic) twins have [47]. More than 70 genes associated with psoriasis have been identified, although to-date they appear to have less than $50 \%$ penetrance. The studies reveal a strong association with HLA (human leukocyte antigen) genes encoded by genes in the 
major histocompatibility complex; in particular, $H L A-C$ (previously called PSORS1), as summarized in Greb et al. (2016) [48]. Genome-wide transcriptome analysis provided additional detail [49].

\subsection{Pathophysiology and Histopathology}

The rather complex mechanisms involved in the etiology, histopathology, and progression of psoriasis are described in detail by Greb et al. (2016) [48], summarized here. External insults (such as physical or chemical trauma, infection, reaction to medicine) initiate the release of endogenous substances ("self-nucleotides"), especially in genetically-predisposed individuals. These can form complexes with substances released by keratinocytes. Multiple steps involve interferons, TNF (tumor necrosis factor), interleukins, vascular adhesion factors, and other pro-inflammatory mediators that also recruit migration of inflammatory cells into the characteristic psoriatic skin lesions.

Epidermal and dermal histologic findings include the following [50]:

\section{Epidermal}

- Mitotic activity of basal keratinocytes is increased almost 50-fold, with keratinocytes migrating from the basal to the cornified layers in only 3 - 5 days rather than the normal 28 - 30 days;

- The epidermis becomes thickened or acanthotic in appearance, and the rete ridges increase in size;

- Abnormal keratinocyte differentiation is noted throughout the psoriatic plaques, as manifested by the loss of the granular layer;

- Alternating collections of neutrophils are sandwiched between layers of parakeratotic stratum corneum, which is virtually pathognomonic for psoriasis.

Dermal

- Signs of inflammation can be observed throughout the dermis;

- Marked hypervascularity and an increase in the size of the dermal papillae occur;

- An activated $\mathrm{CD}^{+}$lymphocytic infiltrate is noted around blood vessels;

- Aggregation of neutrophils in the dermis occurs that extends up into the epidermis.

\section{Psoriatic Arthritis}

Psoriatic arthritis is a comorbidity commonly associated with a large proportion of patients with psoriasis. Indeed, it is one of the most frequent comorbidities associated with psoriasis. The signs and symptoms form a sort of admixture of the two disorders. In addition to the skin-related signs and symptoms, patients also experience joint pain, stiffness, and swelling. It can affect any bony body part, including fingertips and spine, and severity can range from relatively mild to severe. As shown in Figure 5 the ankles and toenails can be severely affected. Most people develop psoriasis first, and are later diagnosed with psoriatic arthritis, but the joint problems can sometimes begin before skin lesions appear [51]. 


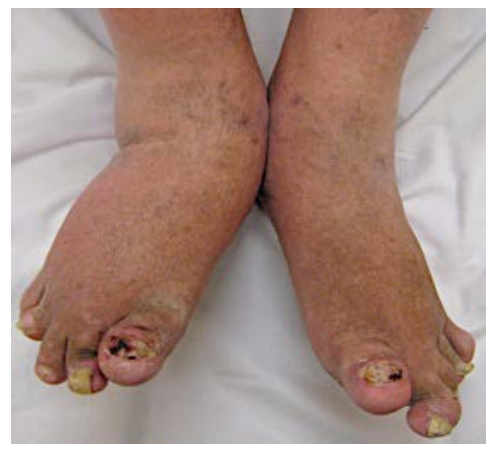

Figure 5. Psoriatic arthritis showing nail involvement (https://en.wikipedia.org/wiki/-Psoriatic_arthritis).

In both disorders, disease flares may alternate with periods of remission.

\subsection{Symptoms}

The signs and symptoms of psoriatic arthritis are similar to those of rheumatoid arthritis (painful joints, swollen, and warm to the touch). Affect joints can be on only one side of the body, or both. However, psoriatic arthritis is more likely to also cause [52]:

- Swollen fingers and toes. Psoriatic arthritis can cause a painful, swelling of fingers and toes. Swelling and deformities can also develop in hands and feet prior to onset of having significant joint symptoms.

- Foot pain. Psoriatic arthritis can cause pain at the points where tendons and ligaments attach to bones-especially at the back of the heel (Achilles tendinitis) or in the sole of the foot (plantar fasciitis).

- Lower back pain. Some people develop spondylitis (inflammation of joints between vertebrae of the spine and in the joints between the spine and pelvis (sacroiliitis)).

Any joint can be affected by psoriatic arthritis. The most common sites are the feet, but also the hands, knees, ankles, shoulders, or elbows. In the early stages, only one or perhaps a few joints are affected, and usually asymmetrically on only one side of the body. As the disease progresses, it becomes more symmetric and polyarticular (involving even five or more joints). Inflammation at the joints can severely limit their movement, and inflammation of the spine can severely limit overall mobility [53].

\subsection{Prevalence and Etiology}

The genetic influence on psoriatic arthritis is quite strong, and penetrance quite high. Heritability is estimated at $80 \%-100 \%$ [54] [55]. The risk of developing psoriatic arthritis is thought to be 30 - to 40 -fold greater if a person's first-degree relative (parent, sibling, or child) has the disorder [54] [55] [56] [57].

Psoriatic arthritis can coexist with other types of arthritic conditions such as rheumatoid arthritis (RA), osteoarthritis (OA), and gout. It is differentiated from RA in that it more commonly affects distal joints asymmetrically, whereas 
RA typically affects proximal small joints of the hands and feet symmetrically. Likewise, the joint-swelling that occurs in psoriatic arthritis is generally soft tissue in nature, in contrast to the bony involvement in OA.

\subsection{Pathophysiology and Histopathology}

Several pathological mechanisms in psoriatic arthritis overlap those in plaque psoriasis, raising the possibility of common treatment. Key mediators in the disease process include, reviewed in detail by Greb et al. (2016) [48], infiltration of $\mathrm{T}$ cells and overproduction of pro-inflammatory cytokines, such as interferons, interleukins, and growth factors. The resultant local inflammatory environment that is thereby established promotes excess remodeling of bone. And in susceptible individuals, feedback loops and amplification factors can perpetuate an initial trigger, involving mediators of the innate immune system, recruitment of additional pro-inflammatory cytokines and chemokines, and angiogenic factors. Antimicrobial peptides also contribute to clinical manifestations of the disease. Undiagnosed or left untreated, symptoms of psoriatic arthritis can rapidly progress to permanent joint erosion and physical disability [58].

\section{Pharmacology of Crisaborole (Eucrisa ${ }^{\circledR}$ )}

\subsection{Preclinical Pharmacology}

Crisaborole, a benzoxaborole derivative, is a small molecular entity with a molecular weight of 251 and empirical formula $\mathrm{C}_{14} \mathrm{H}_{10} \mathrm{BNO}_{3}$. Structure activity relationship analysis among boron containing molecules showed that incorporation of boron into a cyclic structure resulted in greater stability, optimal physiological availability with $\mathrm{p} K_{\mathrm{a}}$ dissociation constants in physiological $\mathrm{pH}$ ranges and a favorable balance of molecule reactivity and target selectivity [32]. The chemical structures of crisaborole and apremilast are shown in Figure 6.

Preclinical studies with crisaborole showed that it had similar binding affinities ( $\mathrm{IC}_{50}$ range: $55-340 \mathrm{nM}$ ) for multiple isoforms of the human PDE4 enzyme,

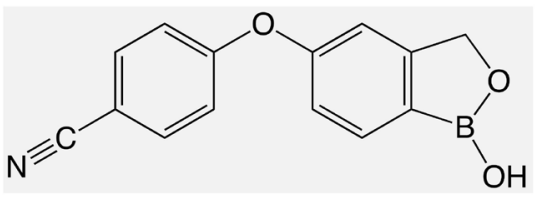

Crisaborole

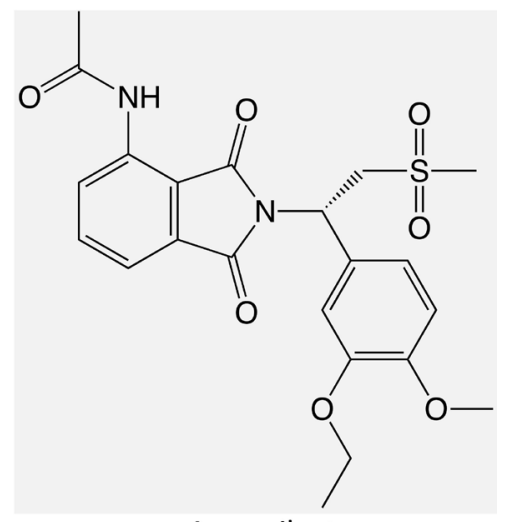

Apremilast

Figure 6. Chemical structures of the PDE4 inhibitors crisaborole and apremilast. Both of these molecules are competitive inhibitors with high affinity binding to the catalytic site of PDE4. 
as did apremilast ( $\mathrm{IC}_{50}$ range: $8.9-48 \mathrm{nM}$ ). Therefore, both inhibitors are not selective for subtypes of PDE4 [11]. In studies designed to correlate the inhibition of PDE4 by inhibitors from various chemical classes (including crisaborole and apremilast) with suppression of cytokine release from stimulated peripheral blood monocytes and purified monocytes, a positive log-linear relationship with slopes ranging from 0.70 to 0.80 was found indicating a relationship between inhibition of PDE4 and suppression of release of TNF- $\alpha$, IL-2, interferon- $\gamma$, IL-5 and IL-23, all mediators involved in the inflammatory response [11].

Additional studies were conducted to assess the effects of PDE4 inhibition on skin thinning, a known adverse event associated with corticosteroid therapy. In this study, conducted in mice, a structural analog of crisaborole was compared to clobetasol, dexamethasone and vehicle. After 16 days of topical exposure to each of these compounds the effect on epidermal and dermal thickness was not significant between the vehicle group and the PDE4 treated group. Clobetasol significantly decreased epidermal thickness while dexamethasone significantly decreased both epidermal and dermal thickness compared to vehicle [11]. These results suggested that crisaborole would have favorable therapeutic effects in the management of $\mathrm{AD}$ and psoriasis. A Phase II clinical trial $(\mathrm{n}=68$; crisaborole $\mathrm{n}$ $=46$; vehicle $\mathrm{n}=22$ ) to evaluate the safety and efficacy of topical crisaborole in plaque psoriasis has recently been completed, and limited data is available [59].

\subsection{Clinical Pharmacology}

Unlike apremilast, which belongs to a different chemical class (Figure 6) and is administered by the oral route, crisaborole is administered via topical application directly to the affected area where it penetrates the epidermis and dermis to reach the site of inflammation [60]. The topical administration of a PDE4 inhibitor in an ointment base also provides the barrier protection and skin hydration requirements for $\mathrm{AD}$ therapy along with the additional anti-inflammatory actions associated with increases in intracellular cAMP. Pharmacokinetic studies were conducted in Phase I clinical trials in pediatric subjects between the ages 2 17 years who also had mild to moderate $\mathrm{AD}$ with a body surface involvement of $49 \% \pm 20 \%$, (mean $\pm \mathrm{SD}$ ), $\mathrm{n}=34$; range: $27 \%-92 \%$ [2]. Doses ranged from 6 $30 \mathrm{~g} /$ application using a $2 \% \mathrm{w} / \mathrm{w}$ ointment base and were applied twice daily. Plasma crisaborole levels were quantifiable in all subjects. In this study the mean maximum plasma concentration after maximal dosing was $111 \mathrm{ng} / \mathrm{ml}$ on day 1 and $127 \mathrm{ng} / \mathrm{ml}$ on day 8 , indicating a low extent of systemic absorption from topical application [60]. In a 29-day Phase II open label study with 23 subjects aged 12 - 17 years the mean plasma $C_{\max }$ and $t_{1 / 2}$ values were $105 \mathrm{ng} / \mathrm{ml}$ and 7.17 $\mathrm{h}$ on day 1 and $94.6 \mathrm{ng} / \mathrm{ml}$ and $11.9 \mathrm{~h}$ on day 8. In vitro studies with human plasma showed that crisaborole is $97 \%$ bound to plasma proteins.

Crisaborole is metabolized into several major inactive metabolites by hydrolysis and oxidation reactions and the major route of excretion is via the kidneys. In vitro studies using human liver microsomes showed that crisaborole and one of 
its principal metabolites are not expected to inhibit cytochrome P450 enzymes $1 \mathrm{~A} 2,2 \mathrm{~B} 6,2 \mathrm{C} 8,2 \mathrm{C} 9,2 \mathrm{C} 19,2 \mathrm{D} 6$ and 3A4 [2]. A second metabolite was also found inactive as an inhibitor of CYP2C19, 2D6 and 3A4; was a weak inhibitor of CYP1A2 and 2B6 and showed moderate inhibitory activity with CYP2C8 and $2 \mathrm{C}$. Because warfarin is primarily metabolized by CYP2C9, a drug-drug potential interaction study was conducted in subjects treated with both crisaborole and warfarin. No significant drug-drug interaction potential was found [2].

Efficacy data were obtained in two multicenter randomized, double-blind, parallel group, vehicle controlled studies involving a total of 1522 subjects from 2 - 79 years of age with a $5 \%$ to $95 \%$ treatable body surface area. The dose for both trials was application of a $2 \%$ ointment or vehicle ointment base twice daily for 28 days. Efficacy was evaluated on day 29 using the Investigator Static Global Assessment scale (ISGA) with success defined as an ISGA score of clear (0), almost clear (1) with a 2-grade or greater improvement from baseline. Results are summarized in Table 3.

The only adverse event (AE) noted in these studies was application site pain such as burning or stinging, observed in 45 subjects (4\%) treated with Eucrisa ${ }^{\circledR}$ compared to 6 subjects $(1 \%)$ in the vehicle group. Treatment with Eucrisa ${ }^{\circledR}$ was well tolerated and no other treatment emergent adverse events observed on the various organ systems were significantly different from those observed in vehicle treated subjects. These results suggest that topical therapy with the PDE4 inhibitor crisaborole could be a viable therapeutic alternative to the traditional standards of therapy.

\section{Pharmacology of Apremilast (Otezla ${ }^{\circledR}$ )}

\subsection{Preclinical Pharmacology}

Apremilast is a phthalimide derivative and has a molecular weight of 460 and empirical formula $\mathrm{C}_{22} \mathrm{H}_{24} \mathrm{~N}_{2} \mathrm{O}_{7} \mathrm{~S}$. As shown in Figure 6, the chemical structure of apremilast is different from that of crisaborole in that it does not contain boron and instead is a sulfonyl isoindole type compound. The basic pharmacology has been well defined in several preclinical studies that explored its anti-inflammatory activity, specificity for PDE isoforms and its efficacy in preclinical models of psoriasis.

In biochemical assays conducted in a partially purified PDE4 enzyme preparation obtained from human monocytes known to contain PDE4B and PDE4D isoform subtypes [61], apremilast was found to have an $\mathrm{IC}_{50}$ of approximately 74

Table 3. Primary efficacy outcomes with mild to moderate AD at day 29 [2].

\begin{tabular}{|c|c|c|c|c|}
\hline & Trial 1 & & Trial 2 & \\
\hline & Eucrisa $(\mathrm{n}=503)$ & Vehicle $(\mathrm{n}=256)$ & Eucrisa $(\mathrm{n}=513)$ & Vehicle $(\mathrm{n}=250)$ \\
\hline Success in ISGA ${ }^{\mathrm{a}}$ & $32.8 \%$ & $25.4 \%$ & $31.4 \%$ & $18.0 \%$ \\
\hline
\end{tabular}


$\pm 34 \mathrm{nM}$ (mean $\pm \mathrm{SD}$ ) and $\mathrm{a} \mathrm{K}_{\mathrm{i}}$ value of $68 \pm 26 \mathrm{nM}$ [62]. In a direct head-to-head comparison of crisaborole and apremilast in a preparation of purified PDE4B2 catalytic domain, Dong et al. found $\mathrm{IC}_{50}$ values of $75 \mathrm{nM}$ and $39 \mathrm{nM}$ for crisaborole and apremilast, respectively [11]. Similar studies by Schafer et al. showed no significant differences in the IC50 values for apremilast in multiple PDE4 isozyme subtypes, indicating no subtype selectivity, similar to crisaborole [11] [62]. Apremilast, at concentrations up to $10 \mu \mathrm{M}$, also showed little or no inhibitory activity with other isozymes in the PDE superfamily.

Other in vitro studies were conducted to examine the effects of apremilast on pro-inflammatory cytokines TNF- $\alpha$, IFN- $\gamma$, IL-12 and IL-23. In a model that uses lipopolysaccharide (LPS) stimulated synthesis of these cytokines in peripheral blood mononuclear cells (PBMC), $10 \mu \mathrm{M}$ apremilast significantly inhibited mRNA expression for each of the cytokines compared to vehicle treated controls [62]. These results show that by increasing intracellular levels of cAMP through PDE4 inhibition, synthesis of chemokines can be inhibited at the level of gene expression, in contrast to directly binding to the chemokine itself, as is the mechanism for several of the IL-targeted monoclonal antibodies [63]. The effects of apremilast on leukotriene $\mathrm{B}_{4}\left(\mathrm{LTB}_{4}\right)$ production were studied in a tissue culture model of polymorphonuclear cells isolated from human leukocytes. $\mathrm{LTB}_{4}$ is an arachidonic acid metabolite of the 5-lipoxygenase pathway and is known to be a pro-inflammatory neutrophil chemoattractant and activator of lymphocytes. Apremilast was added to the tissue culture in a final concentration of $0.01 \%$ for 10 minutes. Apremilast inhibited $\mathrm{LTB}_{4}$ production with an $\mathrm{IC}_{50}$ of 2.5 $\mathrm{nM}$. This unexpected potent effect of apremilast ( $>10$-fold lower than the $\mathrm{IC}_{50}$ for inhibition of PDE4) was attributed to a synergistic action with adenosine, released from the neutrophils. Adenosine can also inhibit $\mathrm{LTB}_{4}$ production via stimulation of adenosine receptors.

The ability of apremilast to alter keratinocyte proliferation was studied in an experimental xenograft mouse model of psoriasis originally developed using psoriatic human skin engrafted onto mice. A modification of this model produces psoriasis-like lesions triggered by psoriatic natural killer cells resulting in lesions involving $\mathrm{T}$ lymphocytes, monocytes, macrophages and dendritic cells and shows similar histopathology to human psoriatic lesions. In this model apremilast $(2.5 \mathrm{mg} / \mathrm{kg} /$ day bid for 14 days) was compared to cyclosporine at the same dose and treatment duration and effects on skin graft tissue histology and immunohistochemistry were analyzed. Both apremilast and cyclosporine reduced epidermal thickness and cellular proliferation significantly compared to vehicle. In 3 of 7 of the mice apremilast was found to completely restore normal histology to the lesions while a partial recovery was observed in 1 of 7 . A similar recovery effect was also noted with cyclosporine [62].

The basic preclinical pharmacologic profile of apremilast shows that it has a high affinity for binding to the catalytic site of all PDE4 subtypes. The effective inhibition of the enzyme leads to sufficient increases in intracellular cAMP levels 
in multiple cell types involved in inflammation. By inhibiting many of the mediators of inflammation and pruritus, apremilast would be expected to be an effective drug for managing inflammatory skin conditions.

\subsection{Clinical Pharmacology}

Apremilast is well absorbed orally (bioavailability $\sim 73 \%$ ), binds with plasma proteins $\sim 68 \%$, and reaches peak plasma concentration $\left(\mathrm{C}_{\max }\right)$ at $\sim 2.5 \mathrm{~h}\left(\mathrm{t}_{\max }\right)$ [64]. It is extensively metabolized via cytochrome (CYP) oxidative metabolism (primarily CYP3A4, with minor contributions from CYP1A2 and CYP2A6) with subsequent glucuronidation, and non-CYP mediated hydrolysis [64]. It has an elimination half-life of $\sim 6-9 \mathrm{~h}$. It is not an inducer or inhibitor of CYP isozymes and is not a substrate or an inhibitor of organic anion transporters. It is a substrate, but not an inhibitor of P-glycoprotein (P-gp). Strong CYP450 inducers reduce concentration and may result in loss of efficacy.

The safety and efficacy of apremilast was evaluated in multi-center, randomized, double-blind, placebo-controlled trials [65] of adult patients with active psoriatic arthritis ( $\geq 3$ swollen joints and $\geq 3$ tender joints of at least 6 months duration) despite prior or current treatment with disease-modifying antirheumatic drug (DMARD) therapy. Patients were allowed to receive stable doses of concomitant methotrexate, sulfasalazine, leflunomide, low dose oral corticosteroids, and/or nonsteroidal anti-inflammatory drugs (NSAIDs) during the trial. Apremilast $30 \mathrm{mg}$ twice daily demonstrated a greater improvement compared to placebo.

Similar results were obtained for patients with psoriasis. The most commonly reported adverse reactions were diarrhea, nausea, headache and upper respiratory tract infection. The long-term safety and tolerability of apremilast was studied in the ESTEEM trials (Efficacy and Safety Trial Evaluating the Effects of Apremilast in Psoriasis) [66]. These trials were Phase III multicenter, randomized, double-blind placebo controlled studies that included patients $\geq 18$ years of age (average age apremilast group: 45.6 years). A total of 1184 patients were treated with apremilast $30 \mathrm{mg}$ po bid for $\geq 3$ years. Patients in both the placebo group and treatment group had significant comorbidities, including hypertension (placebo: $32.1 \%$, apremilast: $30.9 \%$ ), depression (placebo: $13.4 \%$, apremilast: $13.7 \%$ ), hyperlipidemia (placebo: $12.7 \%$, apremilast: $12.6 \%$ ), or Type 2 diabetes (placebo: 9.3\%, apremilast: 10.5\%). In these trials, most AEs were mild to moderate in severity and did not lead to discontinuation of treatment. Diarrhea and nausea, well known AEs associated with PDE4 inhibitors, were mostly mild to moderate in severity, occurred early in the trials and resolved within the first month. The overall conclusion from the ESTEEM trial results were that apremilast had an acceptable safety profile and was generally well tolerated for $\geq 156$ weeks in a psoriatic patient population with several comorbid conditions. These results suggest that apremilast has an acceptable benefit-risk profile that would make it an acceptable treatment option for long term 
management of psoriasis [66].

\section{Pharmacoeconomic Considerations}

Our review of the literature failed to identify any studies that have related clinical outcomes to the costs associated with therapy with either crisaborole or apremilast. In order to provide the reader with some perspective of costs associated with PDE4 inhibitor therapy, this section of the review provides information about the costs that can be expected when using these products to treat their indicated inflammatory skin conditions (atopic dermatitis for Eucrisa ${ }^{\circledR}$ and plaque psoriasis for Otezla ${ }^{\circledR}$ ). For comparative purposes, PDE4 inhibitor therapy is compared to two biologicals recently approved for the management of plaque psoriasis, ustekinumab $\left(\right.$ Stelara $\left.^{\circledR}\right)$ and secukinumab $\left(\right.$ Cosentyx $\left.{ }^{\circledR}\right)$. Each of these biologicals is administered by the subcutaneous route and both are targeted inhibitors of either proinflammatory cytokines IL-17 (secukinumab) or IL-12 and IL-23 (ustekinumab) [67]. Because there are no published data available on this topic, the following assumptions are made:

- All comparisons are based on 28 days of therapy and equieffective outcomes are assumed.

- Costs of drugs were obtained using the lowest price identified on the GoodRx web site [68] and exclude manufacturer coupons and rebates.

- For biologicals, costs are for medication only and exclude additional costs associated with medical supplies needed for aseptic administration.

- Body weight dosages for biologicals are for persons $<100 \mathrm{Kg}(220 \mathrm{lbs})$.

- For Eucrisa ${ }^{\circledR}$ ointment, the clinical Phase I clinical trials for PK data used applications ranging from 6 - 30 g/application bid [2]. For this illustration, a dose of $12 \mathrm{~g}$ bid for 28 days will be used since the product is supplied as 60 and $100 \mathrm{~g}$ tubes; therefore, it is assumed that a $100 \mathrm{~g}$ tube would be preferable in a patient requiring this dosage and would be sufficient for approximately four days of therapy. The following doses were selected for comparison:

- Eucrisa ${ }^{\oplus}$ : prices for $100 \mathrm{~g}$ tubes not available; therefore, instead of $7 \times 100$ g tubes, $12 \times 60 \mathrm{~g}$ tubes required for 28 days of therapy.

○ Otezla ${ }^{\oplus}$ : Since this product requires dose titration beginning with $10 \mathrm{mg}$ po qd followed by bid dosing for 6 days until the maximum therapeutic dose of $30 \mathrm{mg}$ bid is attained, the most economical form of the product to use is the 28-day starter pack.

- Cosentyx ${ }^{\oplus}$ (Novartis): Recommended starting dose is $300 \mathrm{mg} \mathrm{sc}$ at day 0 , then weekly for 4 weeks for a total of 5 doses.

- Stelara ${ }^{\oplus}$ (Janssen): Recommended starting dose is $45 \mathrm{mg} \mathrm{sc}$ on day 0 followed by an additional $45 \mathrm{mg}$ dose in 4 weeks.

Using the assumptions and dosages described above, the following costs were determined: Eucrisa ${ }^{\circledR}: \$ 7334$; Otezla ${ }^{\circledR}: \$ 3268$; Cosentyx $^{\circledR}$ : This would require 5 cartons containing either two prefilled pens or syringes of $150 \mathrm{mg} / \mathrm{syringe/pen}$. Prices for pens and syringes were found to be the same: $\$ 23,195$; Stelara ${ }^{\mathbb{R}}$ : 
$\$ 20,633$. It should be mentioned that these figures are estimates and will vary with geographic location and changing market conditions with time. The costs associated with maintenance therapy cannot be estimated here since the duration and extent of therapy will depend on many factors such as comorbid conditions, concomitant therapy and therapeutic response to each of the treatment types. This illustration is not intended to replace a more thorough pharmacoeconomic evaluation, which will only be possible when much more data including outcomes becomes available for these products.

\section{Discussion}

Based on data reviewed here, it appears that selective PDE-4 inhibitors are an effective therapeutic approach to the management of $\mathrm{AD}$, psoriasis, and psoriatic arthritis. Both preclinical data and results of clinical trials with crisaborole and apremilast show the following:

- Both of the PDE4 inhibitors reviewed here displayed high affinity binding to the catalytic sites of the PDE4B2 subtype with $\mathrm{IC}_{50}$ values $\leq 75 \mathrm{nM}$. Both compounds have variable affinities for other PDE4 subtypes and little or no inhibitory activity against other PDE isozymes.

- Increasing intracellular levels of cAMP leads to favorable therapeutic effects in skin inflammatory disorders that involve tissue infiltration by macrophages, monocytes, neutrophils and T-cells by inhibiting the release of numerous mediators associated with inflammation and itch including decreases in IL-12, IL 17, IL-23, TNF- $\gamma, \mathrm{LTB}_{4}, \mathrm{PGE}_{2}$ as well as other cytokines and chemokines. Increasing cAMP also led to increases in the anti-inflammatory cytokine IL-10.

- Topically applied crisaborole was not associated with any significant adverse events other than localized burning, which resolved over time. Topical administration reduces the risks of GI disturbances associated with orally administered PDE4 inhibitors.

- Orally administered apremilast was associated with a high incidence of headache and GI adverse events including diarrhea, nausea and a somewhat lower incidence of vomiting, all of which resolved within the first two to four weeks of treatment and continued to resolve over time with continued treatment.

- The primary reason that crisaborole is currently only indicated for AD and no other inflammatory skin conditions is that this was the initial indication for which it was developed and additional indications may follow as it is currently in clinical trials for plaque psoriasis.

In conclusion, Therapy with PDE4 inhibitors appears to offer effective management of $\mathrm{AD}$, plaque psoriasis and psoriatic arthritis with lower costs compared to the use of monoclonal antibody targeted therapy. As more efficacy and safety data become available from additional clinical trials and post marketing reports, these products could become valuable alternatives or additions to the 
standard therapy of DMARDs, topical corticosteroids and topical calcineurin inhibitors in the management of these inflammatory skin conditions.

\section{Conflicts of Interest}

The authors declare no conflicts of interest regarding the publication of this paper.

\section{References}

[1] Liu, Y., Wu, E.Q., Bensimon, A.G., et al. (2012) Cost per Responder Associated with Biologic Therapies for Crohn's Disease, Psoriasis, and Rheumatoid Arthritis. Advances in Therapy, 29, 620-634. https://doi.org/10.1007/s12325-012-0035-7

[2] Pfizer (2017) Eucrisa Prescribing Information.

[3] Celgene (2017) Otezla Prescribing Information.

[4] Rall, T.W. and Sutherland, E.W. (1958) Formation of a Cyclic Adenine Ribonucleotide by Tissue Particles. Journal of Biological Chemistry, 232, 1065-1076.

[5] Butcher, R.W. and Sutherland, E.W. (1962) Adenosine 3',5'-Phosphate in Biological Materials. I. Purification and Properties of Cyclic 3',5'-Nucleotide Phosphodiesterase and Use of This Enzyme to Characterize Adenosine 3',5'-Phosphate in Human Urine. Journal of Biological Chemistry, 237, 1244-1250.

[6] Sutherland, E.W. and Rall, T.W. (1958) Fractionation and Characterization of a Cyclic Adenine Ribonucleotide Formed by Tissue Particles. Journal of Biological Chemistry, 232, 1077-1091.

[7] Bender, A.T. and Beavo, J.A. (2006) Cyclic Nucleotide Phosphodiesterases: Molecular Regulation to Clinical Use. Pharmacological Reviews, 58, 488-520. https://doi.org/10.1124/pr.58.3.5

[8] Moustafa, F. and Feldman, S.R. (2014) A Review of Phosphodiesterase-Inhibition and the Potential Role for Phosphodiesterase 4-Inhibitors in Clinical Dermatology. Dermatology Online Journal, 20, 1-10.

[9] Beavo, J.A. (1995) Cyclic Nucleotide Phosphodiesterases: Functional Implications of Multiple Isoforms. Physiological Reviews, 75, 725-748. https://doi.org/10.1152/physrev.1995.75.4.725

[10] Fertig, B.A. and Baillie, G.S. (2018) PDE4-Mediated cAMP Signalling. Journal of Cardiovascular Development and Disease, 5, E8.

[11] Dong, C., Virtucio, C., Zemska, O., et al. (2016) Treatment of Skin Inflammation with Benzoxaborole Phosphodiesterase Inhibitors: Selectivity, Cellular Activity, and Effect on Cytokines Associated with Skin Inflammation and Skin Architecture Changes. Journal of Pharmacology and Experimental Therapeutics, 358, 413-422. https://doi.org/10.1124/jpet.116.232819

[12] Fischmeister, R., Castro, L.R., Abi-Gerges, A., et al. (2006) Compartmentation of Cyclic Nucleotide Signaling in the Heart: The Role of Cyclic Nucleotide Phosphodiesterases. Circulation Research, 99, 816-828. https://doi.org/10.1161/01.RES.0000246118.98832.04

[13] Zhao, C.Y., Greenstein, J.L. and Winslow. R.L. (2015) Interaction between Phosphodiesterases in the Regulation of the Cardiac Beta-Adrenergic Pathway. Journal of Molecular and Cellular Cardiology, 88, 29-38. https://doi.org/10.1016/j.yjmcc.2015.09.011

[14] Serezani, C.H., Ballinger, M.N., Aronoff, D.M. and Peters-Golden, M. (2008) Cyclic 
AMP: Master Regulator of Innate Immune Cell Function. American Journal of Respiratory Cell and Molecular Biology, 39, 127-132. https://doi.org/10.1165/rcmb.2008-0091TR

[15] Dessauer, C.W., Watts, V.J., Ostrom, R.S., Conti, M., Dove, S. and Seifert, R. (2017) International Union of Basic and Clinical Pharmacology. CI. Structures and Small Molecule Modulators of Mammalian Adenylyl Cyclases. Pharmacological Reviews, 69, 93-139. https://doi.org/10.1124/pr.116.013078

[16] Levy, J., Zhou, D. and Zippin, J. (2016) Cyclic Adenosine Monophosphate Signaling in Inflammatory Skin Disease. Journal of Clinical \& Experimental Dermatology Research, 7, 326.

[17] Slominski, A., Zbytek, B., Zmijewski, M., et al. (2006) Corticotropin Releasing Hormone and the Skin. Frontiers in Bioscience, 11, 2230-2248.

https://doi.org/10.2741/1966

[18] Teng, M.W., Bowman, E.P., McElwee, J.J., et al. (2015) IL-12 and IL-23 Cytokines: from Discovery to Targeted Therapies for Immune-Mediated Inflammatory Diseases. Nature Medicine, 21, 719-729. https://doi.org/10.1038/nm.3895

[19] Grewe, M., Bruijnzeel-Koomen, C.A., Schopf, E., et al. (1998) A Role for Th1 and Th2 Cells in the Immunopathogenesis of Atopic Dermatitis. Immunology Today, 19, 359-361. https://doi.org/10.1016/S0167-5699(98)01285-7

[20] Eichenfield, L., Tom, W., Chamlin, S.L., Feldman, S.R., Hanifin, J.M., Simpson, E.L. et al. (2014) Guidelines of Care for the Management of Atopic Dermatitis: Section 1. Diagnosis and Assessment of Atopic Dermatitis. Journal of the American Academy of Dermatology, 70, 338-351. https://doi.org/10.1016/j.jaad.2013.10.010

[21] Hanifin, J.M., Lloyd, R., Okubo, K., Guerin, L.L., Fancher, L. and Chan, S.C. (1992) Relationship between Increased Cyclic AMP-Phosphodiesterase Activity and Abnormal Adenylyl Cyclase Regulation in Leukocytes from Patients with Atopic Dermatitis. Journal of Investigative Dermatology, 98, 100S-105S. https://doi.org/10.1111/1523-1747.ep12462340

[22] Salpietro, D.C., Naccari, F., Polimeni, I. and Pellegrino, C. (1998) Reduced Plasma c-AMP Levels in Children with Atopic Dermatitis. Pediatric Allergy and Immunology, 9, 130-132. https://doi.org/10.1111/j.1399-3038.1998.tb00358.x

[23] Anon (2018) Atopic Dermatitis. Vol. 2018, National Institutes of Health, Bethesda.

[24] Griffiths, C.E.M., van de Kerkof, P. and Czarnecka-Operacz, M. (2017) Psoriasis and Atopic Dermatitis. Dermatologic Therapy, 7, S31-S41. https://doi.org/10.1007/s13555-016-0167-9

[25] Kim, B.E. and Leung. D.Y.M. (2018) Significance of Skin Barrier Dysfunction in Atopic Dermatitis. Allergy, Asthma \& Immunology Research, 10, 207-215. https://doi.org/10.4168/aair.2018.10.3.207

[26] Kim, B.S. (2017) Atopic Dermatitis. https://emedicine.medscape.com/article/1049085-overview

[27] Piliang, M. (2009) Atopic Dermatitis. Vol. 2018, Cleveland Clinic, Cleveland.

[28] Leung, D.Y. and Guttman-Yassky, E. (2014) Deciphering the Complexities of Atopic Dermatitis: Shifting Paradigms in Treatment Approaches. Journal of Allergy and Clinical Immunology, 134, 769-779. https://doi.org/10.1016/j.jaci.2014.08.008

[29] Buys, L.M. (2007) Treatment Options for Atopic Dermatitis. American Family Physician, 75, 523-528.

[30] Ference, J.D. and Last, A.R. (2009) Choosing Topical Corticosteroids. American Family Physician, 79, 135-140. 
[31] Ashcroft, D.M., Dimmock, P., Garside, R., Stein, K. and Williams, H.C. (2005) Efficacy and Tolerability of Topical Pimecrolimus and Tacrolimus in the Treatment of Atopic Dermatitis: Meta-Analysis of Randomised Controlled Trials. BMJ, 330, 516. https://doi.org/10.1136/bmj.38376.439653.D3

[32] Del Rosso, J.Q. and Plattner, J.J. (2014) From the Test Tube to the Treatment Room: Fundamentals of Boron-Containing Compounds and their Relevance to Dermatology. Journal of Clinical and Aesthetic Dermatology, 7, 13-21.

[33] Hanifin, J.M., Chan, S.C., Cheng, J.B., et al. (1996) Type 4 Phosphodiesterase Inhibitors Have Clinical and in Vitro Anti-Inflammatory Effects in Atopic Dermatitis. Journal of Investigative Dermatology, 107, 51-56. https://doi.org/10.1111/1523-1747.ep12297888

[34] Paller, A.S., Tom, W.L., Lebwohl, M.G., et al. (2016) Efficacy and Safety of Crisaborole Ointment, a Novel, Nonsteroidal Phosphodiesterase 4 (PDE4) Inhibitor for the Topical Treatment of Atopic Dermatitis (AD) in Children and Adults. Journal of the American Academy of Dermatology, 75, 494-503. https://doi.org/10.1016/j.jaad.2016.05.046

[35] Butler, J.M., Chan, S.C., Stevens, S. and Hanifin, J.M. (1983) Increased Leukocyte Histamine Release with Elevated Cyclic AMP-Phosphodiesterase Activity in Atopic Dermatitis. Journal of Allergy and Clinical Immunology, 71, 490-497. https://doi.org/10.1016/0091-6749(83)90467-0

[36] Gladman, D.D. (2015) Clinical Features and Diagnostic Considerations in Psoriatic Arthritis. Rheumatic Diseases Clinics of North America, 41, 569-579. https://doi.org/10.1016/j.rdc.2015.07.003

[37] Foundation, N.P. (2018) About Psoriasis. https://www.psoriasis.org/about-psoriasis

[38] WebMD (2018) The Signs and Symptoms of Psoriasis. https://www.webmd.com/skin-problems-and-treatments/psoriasis/psoriasis-signs-s ymptoms

[39] Dalgard, F.J., Gieler, U., Tomas-Aragones, L., et al. (2015) The Psychological Burden of Skin Diseases: A Cross-Sectional Multicenter Study among Dermatological Out-Patients in 13 European Countries. Journal of Investigative Dermatology, 135, 984-991. https://doi.org/10.1038/jid.2014.530

[40] Yeung, H., Takeshita, J., Mehta, N.N., et al. (2013) Psoriasis Severity and the Prevalence of Major Medical Comorbidity: A Population-Based Study. JAMA Dermatology, 149, 1173-1179. https://doi.org/10.1001/jamadermatol.2013.5015

[41] Ahlehoff, O., Gislason, G.H., Charlot, M., et al. (2011) Psoriasis Is Associated with Clinically Significant Cardiovascular Risk: A Danish Nationwide Cohort Study. Journal of Internal Medicine, 270, 147-157. https://doi.org/10.1111/j.1365-2796.2010.02310.x

[42] Gelfand, J.M., Neimann, A.L., Shin, D.B., Wang, X., Margolis, D.J. and Troxel, A.B. (2006) Risk of Myocardial Infarction in Patients with Psoriasis. JAMA, 296, 1735-1741. https://doi.org/10.1001/jama.296.14.1735

[43] Parisi, R., Symmons, D.P., Griffiths, C.E., et al. (2013) Global Epidemiology of Psoriasis: A Systematic Review of Incidence and Prevalence. Journal of Investigative Dermatology, 133, 377-385. https://doi.org/10.1038/jid.2012.339

[44] Rachakonda, T.D., Schupp, C.W. and Armstrong, A.W. (2014) Psoriasis Prevalence among Adults in the United States. Journal of the American Academy of Dermatology, 70, 512-516. https://doi.org/10.1016/j.jaad.2013.11.013

[45] Rahman, P. and Elder, J.T. (2005) Genetic Epidemiology of Psoriasis and Psoriatic Arthritis. Annals of the Rheumatic Diseases, 64, ii37-ii39. 
https://doi.org/10.1136/ard.2004.030775

[46] Lonnberg, A.S., Skov, L., Skytthe, A., Kyvik, K.O., Pedersen, O.B. and Thomsen, S.F. (2013) Heritability of Psoriasis in a Large Twin Sample. British Journal of Dermatology, 169, 412-416. https://doi.org/10.1111/bjd.12375

[47] Lonnberg, A.S., Skov, L., Duffy, D.L., et al. (2016) Genetic Factors Explain Variation in the Age at Onset of Psoriasis: A Population-Based Twin Study. Acta Dermato-Venereologica, 96, 35-38. https://doi.org/10.2340/00015555-2171

[48] Greb, J.E., Goldminz, A.M., Elder, J.T., et al. (2016) Psoriasis. Nature Reviews Disease Primers, 2, Article No. 16082. https://doi.org/10.1038/nrdp.2016.82

[49] Li, J. and Yu, P. (2018) Genome-Wide Transcriptome Analysis Identifies Alternative Splicing Regulatory Network and Key Splicing Factors in Mouse and Human psoriasis. Scientific Reports, 8, Article No. 4124. https://doi.org/10.1038/s41598-018-22284-y

[50] Lui, H. (2018) Plaque Psoriasis. https://emedicine.medscape.com/article/1108072-overview

[51] Gladman, D.D. and Rosen, C.T. (2008) Psoriatic Arthritis. Oxford University Press, Oxford.

[52] Clinic, M. Psoriatic Arthritis. https://www.mayoclinic.org/diseases-conditions/psoriatic-arthritis/symptoms-cause s/syc-20354076

[53] Gladman, D.D., Antoni, C., Mease, P., Clegg, D.O. and Nash, P. (2005) Psoriatic Arthritis: Epidemiology, Clinical Features, Course, and Outcome. Annals of the Rheumatic Diseases, 64, ii14-ii17. https://doi.org/10.1136/ard.2004.032482

[54] Moll, J.M. and Wright, V. (1973) Familial Occurrence of Psoriatic Arthritis. Annals of the Rheumatic Diseases, 32, 181-201. https://doi.org/10.1136/ard.32.3.181

[55] Myers, A., Kay, L.J., Lynch, S.A. and Walker, D.J. (2005) Recurrence Risk for Psoriasis and Psoriatic Arthritis within Sibships. Rheumatology, 44, 773-776. https://doi.org/10.1093/rheumatology/keh589

[56] Chandran, V., Schentag, C.T., Brockbank, J.E., et al. (2009) Familial Aggregation of Psoriatic Arthritis. Annals of the Rheumatic Diseases, 68, 664-667. https://doi.org/10.1136/ard.2008.089367

[57] Karason, A., Love, T.J. and Gudbjornsson, B. (2009) A Strong Heritability of Psoriatic Arthritis over Four Generations-The Reykjavik Psoriatic Arthritis Study. Rheumatology, 48, 1424-1428. https://doi.org/10.1093/rheumatology/kep243

[58] Haroon, M., Gallagher, P. and FitzGerald, O. (2015) Diagnostic Delay of More Than 6 Months Contributes to Poor Radiographic and Functional Outcome in Psoriatic Arthritis. Annals of the Rheumatic Diseases, 74, 1045-1050. https://doi.org/10.1136/annrheumdis-2013-204858

[59] Pfizer (2017) AN2728 Topical Ointment to Treat Mild-to-Moderate Plaque-Type Psoriasis (NCT01300052). Vol. 2018, ClinTrials.gov, Phase 2 Clinical Trial, A Multicenter, Randomized, Double-Blind, 12-Week Study of the Safety and Efficacy of AN2728 versus AN2728 Vehicle in the Treatment of Patients with Mild-to-Moderate Plaque-Type Psoriasis.

[60] Zane, L.T., Chanda, S., Jarnagin, K., Nelson, D.B., Spelman, L. and Gold, L.S. (2016) Crisaborole and Its Potential Role in Treating Atopic Dermatitis: Overview of Early Clinical Studies. Immunotherapy, 8, 853-866. https://doi.org/10.2217/imt-2016-0023

[61] Shepherd, M.C., Baillie, G.S., Stirling, D.I. and Houslay, M.D. (2004) Remodelling 
of the PDE4 cAMP Phosphodiesterase Isoform Profile upon Monocyte-Macrophage Differentiation of Human U937 Cells. British Journal of Pharmacology, 142, 339-351. https://doi.org/10.1038/sj.bjp.0705770

[62] Schafer, P.H., Parton, A., Gandhi, A.K., et al. (2010) Apremilast, a cAMP Phosphodiesterase-4 Inhibitor, Demonstrates Anti-Inflammatory Activity in Vitro and in a Model of Psoriasis. British Journal of Pharmacology, 159, 842-855. https://doi.org/10.1111/j.1476-5381.2009.00559.x

[63] Siebert, S., Tsoukas, A., Robertson, J. and McInnes, I. (2015) Cytokines as Therapeutic Targets in Rheumatoid Arthritis and Other Inflammatory Diseases. Pharmacological Reviews, 67, 280-309. https://doi.org/10.1124/pr.114.009639

[64] Hoffmann, M., Kumar, G., Schafer, P., et al. (2011) Disposition, Metabolism and Mass Balance of Apremilast Following Oral Administration. Xenobiotica, 41, 1063-1075. https://doi.org/10.3109/00498254.2011.604745

[65] Chaplin, S. (2013) Apremilast for the Treatment of Psoriasis and Psoriatic Arthritis. Future Prescriber, 14, 8-9. https://doi.org/10.1002/fps.102

[66] Crowley, J., Thaci, D., Joly, P., et al. (2017) Long-Term Safety and Tolerability of Apremilast in Patients with Psoriasis: Pooled Safety Analysis for $>/=156$ Weeks from 2 Phase 3, Randomized, Controlled Trials (ESTEEM 1 and 2). Journal of the American Academy of Dermatology, 77, 310-317.

https://doi.org/10.1016/j.jaad.2017.01.052

[67] Elyoussfi, S., Thomas, B.J. and Ciurtin, C. (2016) Tailored Treatment Options for Patients with Psoriatic Arthritis and Psoriasis: Review of Established and New Biologic and Small Molecule Therapies. Rheumatology International, 36, 603-612. https://doi.org/10.1007/s00296-016-3436-0

[68] GoodRx (2018). https://www.goodrx.com/ 